\title{
Where has the pollution gone? A survey of organic contaminants in Ho Chi Minh City / Saigon River (Vietnam) bed sediments
}

Marc BABUT ${ }^{a *}$, Brice MOURIER ${ }^{b}$, Marc DESMET ${ }^{c}$, Caroline SIMONNET-LAPRADE ${ }^{d}$, Pierre LABADIE ${ }^{d}$, Hélène BUDZINSKI ${ }^{\mathrm{d}}$, Luiz F. DE ALENCASTRO ${ }^{\mathrm{e}}$, Tran Anh TU ${ }^{f}$, Emilie STRADYg, ${ }^{\mathrm{g} h}$ and Nicolas GRATIOT ${ }^{\mathrm{g}, \mathrm{h}}$

a Irstea, RIVERLY Research Unit, Lyon-Villeurbanne Center, 5 rue de la Doua CS 20244, F-69625 Villeurbanne, France

b Université de Lyon, UMR5023 Laboratoire d'Ecologie des Hydrosystèmes Naturels et Anthropisés, Université Lyon 1, ENTPE, CNRS, 3, rue Maurice Audin, F-69518 Vaulx-en-Velin, France

c GéHCO, Université de Tours, Faculté des Sciences Parc de Grandmont avenue Monge, F- 37200 Tours, France

d CNRS, UMR 5805 EPOC (LPTC Research group), Université de Bordeaux, 351 Cours de la Libération, F-33405 TALENCE, France

e Ecole polytechnique fédérale de Lausanne, Central environmental laboratory (EPFL IIE GR-CEL), Station 2, 1015, Lausanne, Suisse

${ }^{f}$ Faculty of Geology, Ho Chi Minh City University of Technology, 268 Ly Thuong Kiet Street, District 10, Ho Chi Minh City, Vietnam

g Centre Asiatique de Recherche sur l'Eau, Ho Chi Minh University of Technology, 268 Ly Thuong Kiet Street, District 10, Ho Chi Minh City, Vietnam

h University Grenoble-Alpes, UMR5001 CNRS, IRD, Grenoble INP, IGE, CS 40700 F-38000, Grenoble, France

*Corresponding author

Marc BABUT, Irstea, UR RiverLy, Lyon-Villeurbanne Center, 5 rue de la Doua CS 20244, 69625 Villeurbanne, France

(e-mail: marc.babut@irstea.fr )

L.F. de Alencastro current e-mail address: felippe.dealencastro@bluewin.ch

\section{$\underline{\text { Role of the Funding source }}$}

The field work as well as analyses were funded by the Auvergne-Rhône-Alpes Region, through the support afforded by "COOPERA" program (grant CMIRA \# 15005475 01) to the collaborative project "Saigon River - La ville \& le fleuve (2015-2017) : Impacts environnementaux, inondations et contaminations dans une trajectoire historique". The Auvergne-Rhône-Alpes Region was not involved in the study design, nor in data processing, report writing and article submission. 


\section{Abstract}

A wide range of persistent organic chemicals, including polychlorinated biphenyls (PCBs), polycyclic aromatic hydrocarbons (PAHs), some insecticides, as well as polybrominated diphenyl ethers (PBDEs) and some perfluoroalkyl substances (PFASs) were analyzed in 17 bed sediments collected along the Saigon River and at adjacent canal mouths from upstream to downstream in Ho Chi Minh City (Vietnam). Concentrations were rather low for PAHs, as well as for legacy PCBs and dichloro-diphenyl-trichlorethane and metabolites (DDTs), or below detection limits for several PFASs and all PBDEs measured. Several insecticides (chlorpyrifos-ethyl, and the pyrethroids cypermethrin and $\lambda$-cyhalothrin) displayed rather high concentrations at a few sites within the city. There was no distinct upstream - downstream trend for PAHs, (DDTs) or PCBs. Although adjacent canal sediments tended to be more contaminated than Saigon River sediments, the differences were not significant. Emissions are almost certainly substantial for PAHs, and probably also for other contaminants such as PBDEs and some PFASs. During the dry season, contaminants are presumably stored in the city, either in canals or on urban surfaces. Heavy rainfall during the monsoon period carries away contaminated particle flows into the canals and then the Saigon River. The strong tidal influence in the river channel hinders the accumulation of contaminated particles. Contaminated deposits should accordingly be investigated further downstream in depositional environments, such as the mangrove.

\section{Keywords}

sediment, insecticide, PAH, perfluoroalkyl substance, Vietnam, Saigon River 


\section{Introduction}

Vietnam has experienced remarkable economic growth over the last few decades (Du and Fukushima, 2009); this growth has occurred mainly in urban environments, such as Ho Chi Minh City (HCMC). With a population increase from 5 million inhabitants in 1999 (Gubry et al., 2002) to about 8.44 million people or more currently (GSO, 2016), and industrial activities supported by 30,000 small industrial production units and more than 800 large-scale factories located in 15 industrial zones (Strady et al., 2016)], HCMC has emerged as one of the most dynamic big cities in southeast Asia.

As a consequence, anthropogenic pressures on $\mathrm{HCMC}^{\prime}$ s environment have also rapidly increased, leading among others to potential substantial releases of a wide array of organic contaminants into the atmosphere or aquatic media throughout the area. Insecticides have been used for a long time for malaria vector control: Diphenyldiethyl-trichlorethane (DDT) was authorized until 1993 (Kishida et al., 2007); alternative compounds such as organophosphates or pyrethroids have been introduced since then. Industrial production throughout HCMC district include pharmaceuticals, plastics, packaging, textile and leather garments, paints and varnish, and electronics (HEPZA, 2015). In addition, the road traffic in the city and its surroundings is quite intense. Potential emissions accordingly involve a wide range of compounds: DDT and other insecticides, polychlorinated biphenyls (PCBs), polycyclic aromatic hydrocarbons (PAHs), flame retardants, per- and poly-fluorinated substances (PFASs) and so on. Some of them were already monitored in the past, such as PCBs (Phuong et al., 1998; Kishida et al., 2007; Minh et al., 2007; Nguyen, 2009), DDT and its metabolites (Phuong et al., 1998; Kishida et al., 2007), and PAHs (Kishida et al., 2007). Monitoring data on other contaminants such as polybrominated diphenyl ethers (PBDEs) are still rare or absent.

The study objectives were to provide an up to date diagnosis of the contamination of Saigon River sediments by a range of historical and emerging chemicals. Based on the available knowledge (Phuong et al., 1998; Kishida et al., 2007; Minh et al., 2007; Nguyen, 2009), a moderate/decreasing contamination by legacy chemicals such as DDT and PCBs was expected, as well as an increasing contamination throughout the urbanized river stretch for chemicals related to industries or consumer products (flame retardants and PFASs) and road traffic (PAHs). 


\section{Materials and methods}

\subsection{Study area}

Ho Chi Minh City (HCMC) is located along the Saigon River, which is a tributary of the Dongnai River (Figure 1).

The respective catchments cover $4700 \mathrm{~km}^{2}$ and $40000 \mathrm{~km}^{2}$ respectively, and are subject to a monsoon regime, with about 150 rainy days between May and late November and an average annual rainfall of $1800 \mathrm{~mm}$ (GSO, 2016). Both river flows are regulated by upstream reservoirs, namely Dau Tieng on the Saigon River and Tri An on the Dongnai River (Figure 1-B). Respective mean discharges are estimated around 50-60 and $600-650 \mathrm{~m}^{3} \mathrm{~s}^{-1}$ (Ha, 2009; Camenen et al., 2017). Given the low altitude and the flat topography, this system is subject to a strong tidal influence, far upstream from the urbanized areas.
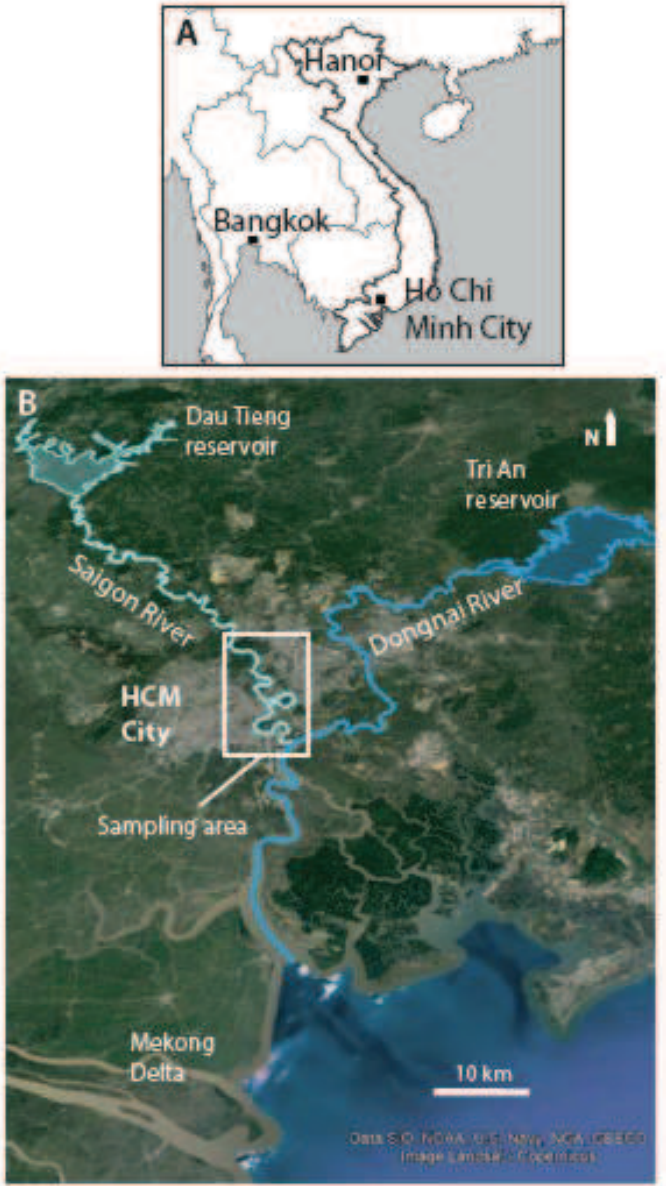

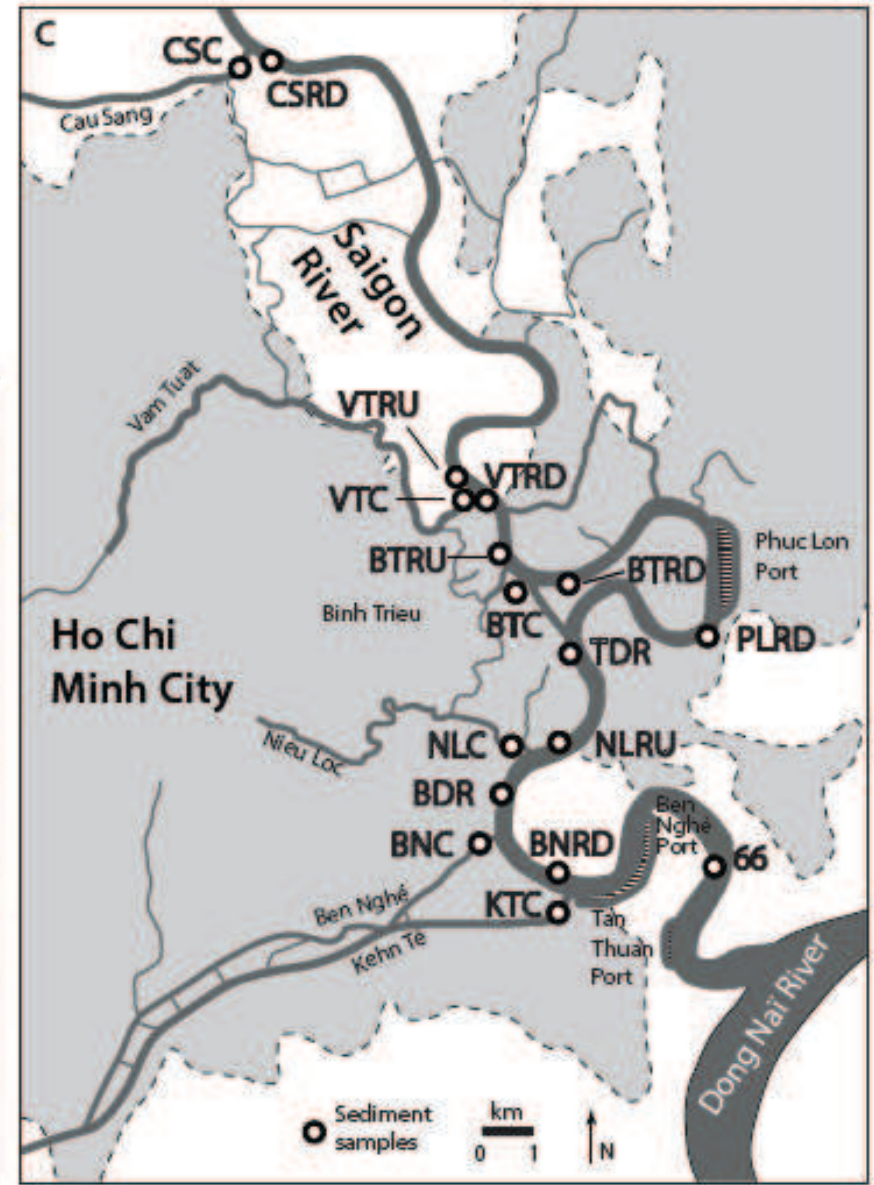

Figure 1 - Study area (A- regional map; B- HCMC area; C- sampling sites in HCMC)

\subsection{Sediment sampling}

The top $5 \mathrm{~cm}$ of bed sediment deposits were sampled with an Eckman grab operated from a boat for the river sites, and from the shore for canal sites (see locations in Figure 1-C). Eleven samples were collected in the Saigon River along an upstream-downstream gradient, and six samples were collected in canals close to their confluence 
with the Saigon River between the $5^{\text {th }}$ and the $8^{\text {th }}$ of January, 2016. Details on the sampling locations are provided in the Supplementary Information (SI), Table S1.

\subsection{Sediment characteristics}

The organic matter (OM) content was estimated by loss on ignition (LOI) at $550^{\circ} \mathrm{C}$ on bulk sediment following Heiri et al. (2001); the results are expressed as a percentage of the sediment sample mass (\% dw). Grain size distributions were determined by sonicating and then analyzing each sample with a Mastersizer $3000^{\circledR}$ laser mounted with a hydro-SM small-volume dispersion unit (Malvern Instruments, Worcestershire, UK). Grain-size fractions, mode, sorting, and skewness were computed using the Gradistat program (Blott and Pye, 2001).

\subsection{Chemical analysis}

\subsubsection{Chlorinated pesticides, polychlorinated biphenyls (PCBs), polycyclic aromatic hydrocarbons (PAHs)} and polybrominated diphenyl ethers (PBDEs)

These compounds were analyzed following the approach described in previous papers (Thevenon et al., 2013; Mwanamoki et al., 2014; Kilunga et al., 2017). Briefly, sediment samples were first freeze-dried and sieved $(2 \mathrm{~mm})$. Then, after addition of internal standards $\left({ }^{13} \mathrm{C}\right.$-labeled for halogenated compounds and ${ }^{2} \mathrm{H}$-labeled compounds for all PAHs), about $5 \mathrm{~g}$ of dry sediment were extracted with a mixture of $20 \%$ acetone in hexane (v/v) into a Soxhlet system. Interfering sulfur compounds were removed by addition of activated copper to the extract. Then, the organic extract was concentrated to $1 \mathrm{~mL}$ in a vacuum rotary evaporator (Buchi Rotavapor, Flawil, Switzerland). The extract was further submitted to fractionation and clean-up over a chromatographic column containing $3 \mathrm{~g}$ of Silicagel, according to de Boer et al. (2001). Three separated fractions were collected: first with $16 \mathrm{~mL}$ of hexane, then $35 \mathrm{~mL}$ of hexane, and finally $50 \mathrm{~mL}$ of hexane: dichloromethane $(\mathrm{v} / \mathrm{v}, 1: 1)$. The first two fractions contained PCBs and PBDEs respectively. PAHs and chlorinated pesticides were distributed into the three fractions, which were analyzed separately. After reducing the volume again, the chemicals were measured by gas chromatography with triple mass spectrometry detection (GC-MS/MS, Thermo Scientific, TSQ Quantum XLS Ultra, Waltham, MA, USA). Two columns with different polarities, a ZB-5ms column (60 m x 0.25 $\mathrm{mm} \times 0.25 \mu \mathrm{m})$ and one ZB-XLB column $(20 \mathrm{~m} \times 0.18 \mathrm{~mm} \times 0.18 \mu \mathrm{m})$, were used for separation and identification of the different compounds. The list of compounds analyzed with this approach is provided in the SI, section 2. 


\subsubsection{Per- and poly-fluorinated alkyl substances (PFASs)}

PFASs were analyzed following the method described in (Munoz et al., 2015) and (Bertin et al., 2014). Briefly freeze-dried / sieved sediment samples ( $1 \mathrm{~g}$ dry weight) were spiked with a suite of ${ }^{13} \mathrm{C}$-labeled internal standards; PFASs were extracted by sonication using methanol $(\mathrm{MeOH})$, concentrated under a nitrogen stream, purified on ENVI-Carb cartridge.es and eluted with $\mathrm{MeOH}$. Eluates were concentrated to $400 \mu \mathrm{L}$ under a nitrogen stream and transferred into injection vials. PFASs (list of compounds and acronyms in the SI, Table S3) were analyzed by LCMS/MS using an Agilent 1200 LC system (Agilent Technology, Massy, France) interfaced with an Agilent 6490 triple quadrupole mass spectrometer. Standards and reagents were purchased from Wellington Laboratories (via BCP Instruments, Irigny, France) and Sigma-Aldrich (St Quentin Fallavier, France).

\subsubsection{QA/QC}

Almost all chlorinated pesticides, PCBs and PBDEs were included in the second round of UNEP-coordinated Global Interlaboratory Assessment 2012/2013 (UNEP, 2014). In this exercise dozens of laboratories analyzed the same sediment sample. Results from our team are presented in the SI, Table S2. Additionally, other pesticides such as chlorpyrifos-methyl and -ethyl, endosulfan I, II and -sulfate, endrin aldehyde and -ketone, methoxychlor, acetochlor, $\lambda$-cyhalothrin, $\alpha$ and $\beta$-cypermethrin and deltamethrin were also analyzed. Recovery rates for PCBs varied between $80.5 \%$ and $85.3 \%$, and between $61.3 \%$ and $103.7 \%$ for PAHs. PBDE recovery rates varied between $80.3 \%$ and $94.7 \%$, while for pesticides they ranged from $51.5 \%$ (endosulfan) to $90.4 \%(\delta-\mathrm{HCH})$. The limits of detection (LODs) are indicated in Table S2 in the SI.

The PFAS recovery rates varied between 65 and $90 \%$ in spiked reference sand samples $\left(0.5 \mathrm{ng} \mathrm{g}^{-1}\right.$ for each analyte, $n=3$ ). In addition, accuracy was also estimated using spiked sand; both internal standards and analytes were added at the start of the experiment. Accuracy rates ranged from 75 to $115 \%(n=3)$.

Procedural blanks consisting of $10 \mathrm{~mL}$ of $\mathrm{MeOH}$ were analyzed for each sample series and, when applicable, PFAS concentrations were blank-corrected. The LODs are indicated in Table S5 (section D) in the SI. All results are expressed in $\mathrm{ng} \mathrm{g}^{-1}$ dry weight $(\mathrm{dw})$.

\subsection{Statistics}

We used Pro-UCL 5.0 software (https://www.epa.gov/land-research/proucl-software ) to determine compound distributions accounting for left-censored results. Wilcoxon-Mann-Whitney (pair comparison) tests were applied 
to compare contamination levels between groups, using Pro-UCL 5.0. Sum parameters, i.e. the sum of concentrations for chemicals of a given family (PAHs, PCBs and so on) were determined as the sums of concentrations above the LD or LoR. Spatial trends were assessed using non-parametric Mann-Kendall and TheilSen tests (Pro-UCL 5.0), thus making it possible to handle left-censored data. These tests were not applied when detection frequency fell below $70 \%$.

The significance threshold was set at 0.05 in all analyses.

\section{Results}

\subsection{Sediment characteristics}

Grain size distributions in the 17 bed sediments presented three modes at $6.3 \mu \mathrm{m}, 15.4 \mu \mathrm{m}$ and above $800 \mu \mathrm{m}$. Most samples were mainly composed of rather fine particles (poorly sorted silts), with four outliers having a median grain size (D50) of $1039.2 \pm 108.3 \mu \mathrm{m}$ (coarse sand). When these outliers are removed, the median grain size $(16.5 \pm 12.0 \mu \mathrm{m})$ and grain size distributions in canal samples did not differ from those in river samples ( $p$ value $=0.421)$. The OM content in bed sediments presented an average value of $7.8 \pm 2.5 \%$, with one outlier having an OM content below $2 \%$. Furthermore, respective OM contents in canal and river samples did not differ $(p$-value $=0.119)$. Detailed results are provided in the SI (Table S4).

\subsection{Sediment contamination}

The detection rates of the 95 analytes ranged from 0 to $100 \%$ of the 17 bed sediment samples. PBDE concentrations, as well as those of hexachlorobenzene $(\mathrm{HCB})$, hexachlorocyclohexane $(\mathrm{HCH})$, drins, heptachlor, endosulfan and deltamethrin were systematically below their respective LODs. Detection rates of other insecticides ranged from $12 \%$ (cypermethrin) to 94\% (chlorpyrifos-ethyl, $\Sigma$ DDTs). Furthermore, PCB detection rates ranged from $12 \%$ for the congener PCB156 (mono-ortho substituted) to $88 \%$ for more stable congeners such as PCB153 (Table S5-A in the SI). DDT isomers and their metabolites occurred in 76 to $94 \%$ of the samples, except $0, p^{\prime}$-DDT (41\%); overall, some parent compounds and metabolites were present in $100 \%$ of the samples (Table S5-B in the SI). Similarly, most PAHs were present in all samples, with individual detection rates ranging from $82 \%$ (acenaphtene, dibenzo(a,h)anthracene) to $100 \%$ (Table S5-C in the SI). The most frequently detected PFASs included two carboxylic acids (PFUnDA, PFTrDA), PFOS isomers, FOSA, EtFOSAA, some polyfluoroalkyl phosphoric acid diesters (6:2 and 8:2 diPAP) and fluorotelomer sulfonates (8:2 FTSA; Table S5-D and E in the SI). 


\subsubsection{Insecticides}

Chlordane $\alpha$ and $\gamma$ isomers were detected in four samples, at concentrations close to the LOD (0.2 $\left.\mathrm{ng} \mathrm{g}^{-1} \mathrm{dw}\right)$. $\Sigma D D T$, i.e. the sum of concentrations of DDT isomers and their metabolites, were determined in all samples, and varied between $2.40 \mathrm{ng} \mathrm{g}^{-1} \mathrm{dw}$ and $16.05 \mathrm{ng} \mathrm{g}^{-1} \mathrm{dw} ; p, p^{\prime}$ DDD and $p, p^{\prime}$ DDE were predominant throughout the samples. DDDT concentrations in canal samples were slightly lower than in river samples, but the difference was not significant ( $p$-value 0.17 , Table 1$)$.

The pyrethroid insecticide $\lambda$-cyhalothrin, was measured at two canal sites $\left(0.91\right.$ and $\left.23.2 \mathrm{ng} \mathrm{g}^{-1}\right)$, plus an adjacent river site $\left(0.97 \mathrm{ng} \mathrm{g}^{-1}\right)$ for $\lambda$-cyhalothrin, at concentrations several orders of magnitude above the detection limit (0.3 ng g-1 dw; Table S5-B in the SI).

\subsubsection{PCBs}

With a maximum $\Sigma$ PCB7 of $18.7 \mathrm{ng} \mathrm{g}^{-1} \mathrm{dw}$ (sum of indicator congener concentrations, i.e. CB 28, 52, 101, 118, 138,153 and 180), or $25.3 \mathrm{ng} \mathrm{g}^{-1} \mathrm{dw}$ for $\Sigma 12 \mathrm{PCB}$ (12 measured congeners), the contamination by this class of compounds remained moderate, as compared e.g. to existing sediment quality guidelines (MacDonald et al., 2000). For two samples (CSC, BNRD), all analyzed congeners were < LOD. Otherwise, the molecular profiles were dominated by congeners 138,153 and 180 , with median values equaling $0.27 \mathrm{ng} \mathrm{g}^{-1} \mathrm{dw}, 0.51 \mathrm{ng} \mathrm{g}^{-1} \mathrm{dw}$, and 0.22 $n g^{-1} \mathrm{dw}$ respectively.

\subsubsection{PAHs}

$\Sigma$ PAHs (i.e. the sum of the concentrations of the 16 compounds) varied between $49 \mathrm{ng} \mathrm{g}^{-1} \mathrm{dw}$ and $933 \mathrm{ng} \mathrm{g} \mathrm{g}^{-1} \mathrm{dw}$ (median $345 \mathrm{ng} \mathrm{g}^{-1} \mathrm{dw}$; SI Table S5-C), well below existing sediment quality guidelines (e.g. MacDonald et al., 2000). Phenanthrene, fluoranthene, pyrene and benzo(b)fluoranthene were the main contributors to $\Sigma$ PAHs, representing respectively $12 \%, 17 \%, 14 \%$ and $11 \%$ of the sum on average (Figure S1 in SI). Whereas phenanthrene is deemed to result mainly from OM maturation, i.e., petrogenic origin, fluoranthene and pyrene instead point to pyrogenic sources, such as vehicle exhaust or wood coal combustion (Zhang et al., 2013). Applying concentration ratios between specific PAHs (Yunker et al., 2002) tended to confirm this diagnosis of multiple sources, with a predominance of pyrogenic sources (Figure S2 in the SI). Nevertheless $\Sigma$ PAHs in all samples remained below the probable effect concentration of $2280 \mathrm{ng} \mathrm{g}^{-1} \mathrm{dw}$ (MacDonald et al., 2000). 


\subsubsection{PFASs}

Overall, the PFASs detected displayed rather low concentrations, e.g. PPFCAs, 8:2 FTSA, 6:2 di-PAP and 8:2 diPAP maximum concentrations at $1.18 \mathrm{ng} \mathrm{g}^{-1} \mathrm{dw}, 0.08 \mathrm{ng} \mathrm{g}^{-1} \mathrm{dw}, 0.18 \mathrm{ng} \mathrm{g}^{-1} \mathrm{dw}_{\mathrm{w}}$ and $0.24 \mathrm{ng} \mathrm{g}^{-1} \mathrm{dw}$ respectively (Table S5-E in the SI) compared to studies in various environments (Ahrens et al., 2010; Chen et al., 2017; Munoz et al., 2017).

\subsection{Contamination patterns}

There is no upstream-downstream gradient in Saigon river sediments for PAHs, DDTs, PCBs or PFOS (Figure 2). Unlike PAHs, chlorpyrifos-ethyl presented a significant upstream-downstream trend ( $p$-value 0.03; Figure 2-D), with two peaks at CSRD, immediately downstream from the Cau Sang canal junction, and BTRD, immediately downstream from the Binh Trieu canal junction. The two corresponding canal sites, i.e. CSC and BTC (not shown in Figure 2, which displays only sampling sites in the river), also displayed appreciable chlorpyrifos-ethyl concentrations compared to other sites in this study, though below those observed at CSRD and BTRD. The BTC sample, but not CSC, also revealed noticeable concentrations of $\lambda$-cyhalothrin $\left(23.2 \mathrm{ng} \mathrm{g}^{-1} \mathrm{dw}\right)$ and cypermethrin (155 $\mathrm{ng} \mathrm{g}^{-1} \mathrm{dw}$ ). While canal sediments showed higher concentrations than river sediments for the most significant (Table 1). 


\section{A- $\Sigma$ PAHs}

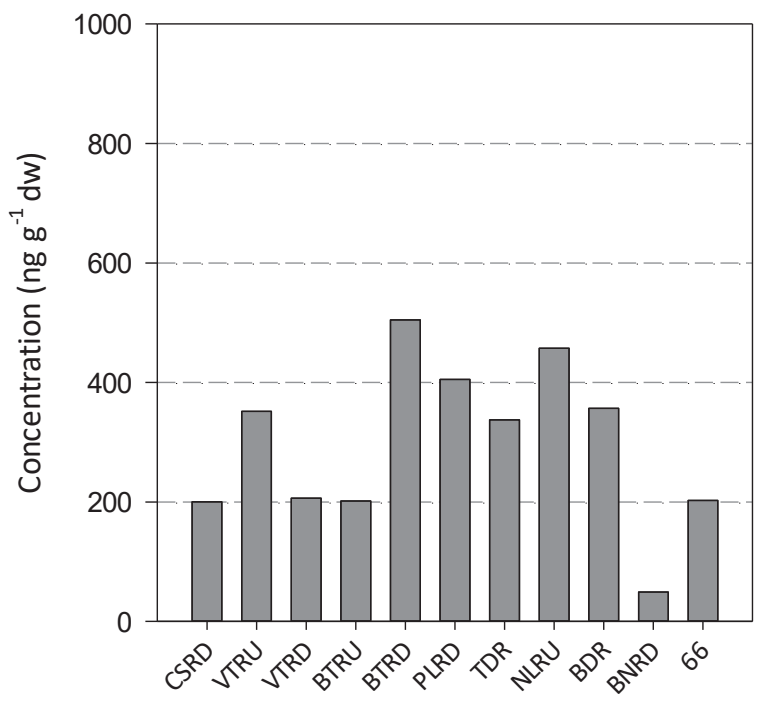

C - PFOS

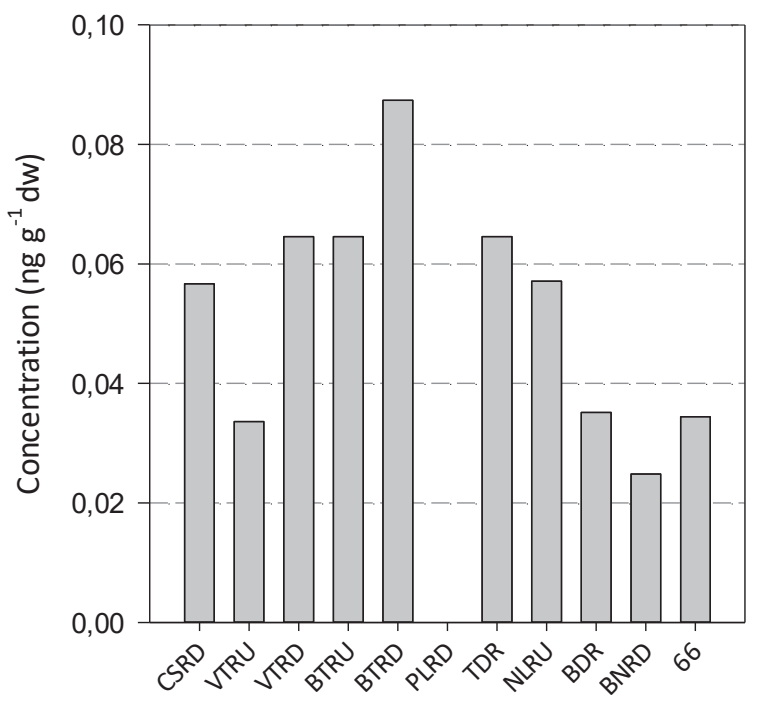

Sites
B - $\Sigma$ PCB7 \& $\Sigma$ DDTs

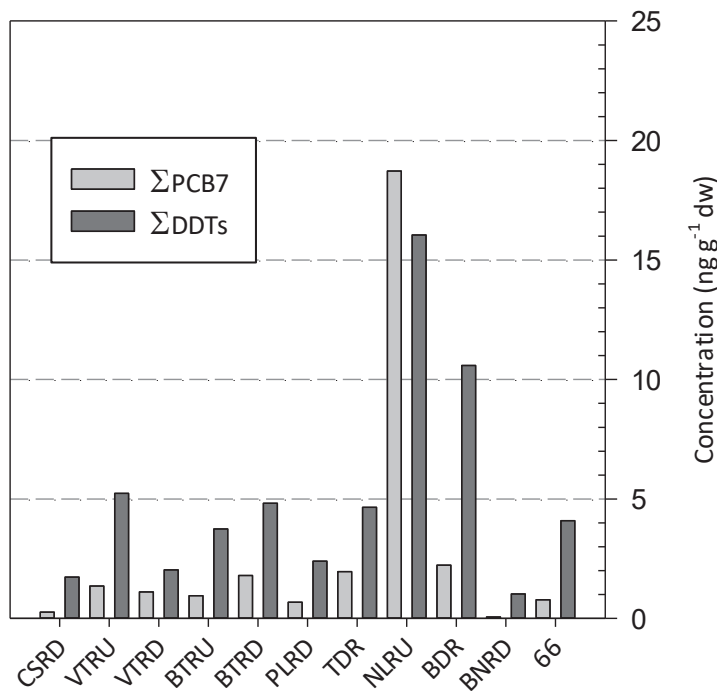

D - Chlorpyrifos-ethyl

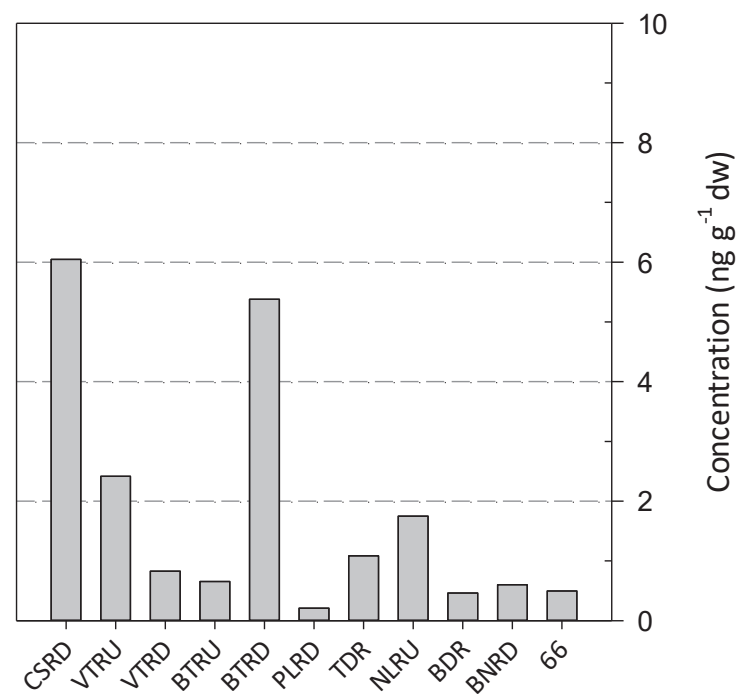

Sites

Figure 2 - PAHs, PCBs, DDTs, PFOS, and Chlorpyrifos-ethyl in Saigon River sediments from upstream (CSRD) to downstream (66) of HCMC 


\begin{tabular}{|c|c|c|c|c|c|}
\hline \multirow[b]{2}{*}{ Contaminant } & \multicolumn{2}{|c|}{ Canals } & \multicolumn{2}{|c|}{ River } & \multirow[b]{2}{*}{$p$-value } \\
\hline & Mean (SD) & $\begin{array}{c}\text { Median } \\
\text { (min-max) }\end{array}$ & Mean (SD) & $\begin{array}{c}\text { Median } \\
\text { (min-max) }\end{array}$ & \\
\hline Chlorpyrifos-ethyl & $2.00(0.72)$ & $1.93(1.26-2.82)$ & $1.97(2.07)$ & $0.95(0.46-6.05)$ & 0.09 \\
\hline$\Sigma \mathrm{DDT}$ & 8.02 (3.10) & $\begin{array}{c}7.48 \text { (<LOD- } \\
13.05)\end{array}$ & $5.13(4.45)$ & $\begin{array}{c}4.10 \text { (<LOD- } \\
16.05)\end{array}$ & 0.17 \\
\hline$\Sigma \mathrm{PAHS}$ & $498(308)$ & 503 (108-933) & $298(136)$ & 337 (49-505) & 0.09 \\
\hline$\Sigma \mathrm{PCB} 7$ & $3.95(2.15)$ & 3.69 (<LD-7.32) & $2.99(5.56)$ & $\begin{array}{c}1.24 \text { (<LOD- } \\
18.73)\end{array}$ & 0.09 \\
\hline$\Sigma$ PFASs & $0.86(0.539)$ & $0.544(<\mathrm{LQ}-1.60)$ & $0.39(0.281)$ & $0.37(<L Q-0.92)$ & 0.08 \\
\hline
\end{tabular}

Table 1 - Comparison of the concentrations ( $\mathrm{ng} \mathrm{g}^{-1} \mathrm{dw}$ ) in canal and river sediments (Mann-Whitney test)

\section{Discussion}

\subsection{Sediment quality - Comparison to other studies}

DDT compounds have been measured in HCMC sediment samples since the 1990s: Phuong et al. mentioned a ¿DDTs up to $253 \mathrm{ng} \mathrm{g}^{-1} \mathrm{dw}$, with a median value of $49 \mathrm{ng} \mathrm{g}^{-1} \mathrm{dw}$ in canal sediments (Phuong et al., 1998), while about 10 years later the concentration ranges were $12-72 \mathrm{ng} \mathrm{g}^{-1} \mathrm{dw}$ in canal sediments, and $0.21-23 \mathrm{ng} \mathrm{g} \mathrm{dw}^{-1}$ in Saigon and Dongnai river sediments (Minh et al., 2007). At the same period, another study in canal and river sediments showed LDDTs ranging from 0.1 to $38.3 \mathrm{ng} \mathrm{g}^{-1} \mathrm{dw}$ (Kishida et al., 2007), similar to the recent findings $\left(1.8-74 \mathrm{ng} \mathrm{g}^{-1} \mathrm{dw}\right)$ by Bui et al. (2016). Although it was not possible to compute these data in a single trend assessment, in part because most locations are not accurately reported in previous studies, there is no evidence of a sharp EDDT decline in the last two decades. Overall, even the highest concentrations recorded in 1998 remained far below the probable effect concentration of $572 \mathrm{ng} \mathrm{g}^{-1} \mathrm{dw}$ derived from co-occurrence studies in North America (MacDonald et al., 2000).

Measured concentrations of $\lambda$-cyhalothrin were close to, or largely exceeded the proposed sediment quality guideline (Ineris) of $1.05 \mathrm{ng} \mathrm{g}^{-1}$, and similar to levels causing adverse effects to Chironomus dilutus larvae in sediments from Pearl River tributaries in China (Cheng et al., 2017). Cypermethrin, another pyrethroid for which no guideline could be identified, was measured at the same canal sites at (14.8 and $155 \mathrm{ng} \mathrm{g}^{-1}$ ). Many pyrethroid insecticides, including permethrin, bifenthrin, and phenothrin were recently identified in HCMC sediments, with particularly high concentrations for permethrin (up to $578 \mathrm{ng} \mathrm{g}^{-1} \mathrm{dw}$ for the cis-isomer and $3693 \mathrm{ng} \mathrm{g}^{-1} \mathrm{dw}$ for the trans-isomer) and bifenthrin (477 $\mathrm{ng} \mathrm{g}^{-1} \mathrm{dw}$; Bui et al., 2016). Furthermore, chlorpyrifos-ethyl displayed concentrations between <LOD $\left(0.3 \mathrm{ng} \mathrm{g}^{-1} \mathrm{dw}\right)$ and $6.05 \mathrm{ng} \mathrm{g}^{-1} \mathrm{dw}$ (median $1.27 \mathrm{ng} \mathrm{g}^{-1} \mathrm{dw}$; Table S5-B in the SI), overlapping the range reported in Bui et al., (2016), namely $1.8-38.8 \mathrm{ng} \mathrm{g}^{-1} \mathrm{dw}$. For both pyrethroid insecticides 
and chlorpyrifos, the higher concentrations reported by this study (Bui et al., 2016) were for canal sites quite far from the river, contrary to the present study.

PCB concentrations are similar to or lower than previous observations, with concentrations in canal sediments ranging from 5 to $123 \mathrm{ng} \mathrm{g}^{-1} \mathrm{dw}$ for the sum of six indicator congeners (Phuong et al., 1998), or 0.19 to $110 \mathrm{ng} \mathrm{g}^{-}$

${ }^{1} \mathrm{dw}$ for the sum of homolog series (Kishida et al., 2007). A previous study reported $\Sigma$ PCBs between 46 and 150 $\mathrm{ng} \mathrm{g} \mathrm{g}^{-1} \mathrm{dw}$ in canal sediments, and between 0.33 and $22 \mathrm{ng} \mathrm{g}^{-1} \mathrm{dw}$ in the sediments from the Saigon and Dongnai rivers (Minh et al., 2007). Again, it is not possible to assess temporal trends on the basis of these results, because of methodological differences such as the list of measured congeners, the presentation of the results or the lack of details on sampling locations.

PAH concentrations are similar to recent findings in HCMC canals, except one site (2339 $\left.\mathrm{ng} \mathrm{g^{-1 }} \mathrm{dw}\right)$ close to an industrial area (Bui et al., 2016). An array of about 60 PAHs having two to six rings were analyzed in canal and river sediments 15 years ago (Kishida et al., 2007). The results are reported by category (two rings, three rings and so on), making it difficult to compare them accurately with our data. Nevertheless, by comparing the sum of concentrations of the compounds common to both studies, the range of values is larger in Kishida et al. (2007)

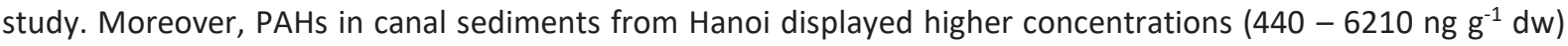
than in the present study (Boll et al., 2008); PAHs in sediments from five sites along the river Kim Nguu in Hanoi city center, were much higher (21.800 - $75100 \mathrm{ng} \mathrm{g}^{-1} \mathrm{dw}$; Hung et al., 2014) than in HCMC river sediments.

To our knowledge, PFAS measurements in sediments are currently missing in HCMC waterways. As an indication, the $\Sigma$ PFASs median concentration in French river sediments was $0.48 \mathrm{ng} \mathrm{g}^{-1} \mathrm{dw}$ in 2012 (Munoz et al., 2015), while we observed a median of $0.16 \mathrm{ng} \mathrm{g}^{-1} \mathrm{dw}$ in HCMV. Note that the French study cited included remote, rural, urban and industrial sites, while the 17 sites investigated in this study should all be considered as urban or mixed (urban-industrial), except the upstream sites. To our knowledge, only two other studies attempted to capture PFAS contamination in Vietnamese aquatic environments. A nationwide study conducted in 2013 looked for 11 fluoroalkyl carboxylates (PFCAs) and five sulfonates (PFSAs) in water samples, including three sites in the Saigon River, and six in HCMC canals, rather far from the river (Duong et al., 2015). Concentrations of short-chain PFCAs (PFPeA, PFHxA and PFHpA), as well as those of PFOA or PFOS, reached several ng $\mathrm{L}^{-1}$ at some canal sites. Longerchain PFCAs were not detected. Another study throughout Vietnam conducted in 2013 and 2015 looked for nine PFCAs (from PFHxA to PFTeDA) and four PFSAs (from PFBS to PFDS) in unfiltered water and sediment samples. 
This study included three sampling sites in HCMC along the Saigon River, two sites in the Dongnai River upstream from its confluence with the Saigon River, and four downstream, and eight sites influenced by waste water treatment plant (WWTP) effluents (Lam et al., 2017). The sum of PFAS concentrations in Saigon River water samples varied between 1.7 and $14.6 \mathrm{ng} \mathrm{L}^{-1}$ and did not exceed $4.2 \mathrm{ng} \mathrm{L}^{-1}$ in Dongnai River water samples, while it reached $107 \mathrm{ng} \mathrm{L}^{-1}$ in WWTP/canal samples. Except for PFHxS (detected in $\approx 50 \%$ sediment samples), and several long-chain PFCAs (PFDA, PFUnDA and PFTrDA, detected once out of 11 sites) and PFOS (four sites out of 11), most analyzed PFASs remained below the respective LOQs in sediment samples; however the LOQs reported were generally higher (0.04 $-0.30 \mathrm{ng} \mathrm{g}^{-1} \mathrm{dw}$ depending of the compound) than those obtained in the present study.

\subsection{Organic contaminant fate in Saigon River and canals in HCMC}

According to the results of the present study, bed sediments of the Saigon River are weakly contaminated. This is not necessarily surprising for legacy chemicals, such as DDT, which was prohibited in 1993 in Vietnam (Kishida et al., 2007), or PCBs, of which import ceased in 1985 (World-Bank, 2009). This was less expected for more recent substances, such as PBDEs or PFASs, or continuously emitted by multiple sources, such as PAHs. Indeed, PAH concentrations in HCMC are low compared to other urban rivers and canals in the region, such as Hanoi (Kishida et al., 2007; Boll et al., 2008; Hung et al., 2014) and Bangkok (Boonyatumanond et al., 2006) to a lesser extent. The PAH concentrations in Saigon River sediments were similar to those of rural areas or remote (i.e. reference) sites elsewhere in Vietnam (Kishida et al., 2007; Boll et al., 2008). However, some sampling sites in Hanoi studies were presumably located closer to industrial releases than the HCMC sampling sites. After removal of these assumed outliers, the range of $\Sigma \mathrm{PAHs}$ observed in Hanoi canal and river sediments remained higher than in HCMC canal sediments, but similar to Bangkok canal sediments (Figure 3). Interestingly, there is a strong contrast between PAH concentrations in Bangkok canals and in the Chao-Praya River, which flows through this city, and shortly after into the sea. 


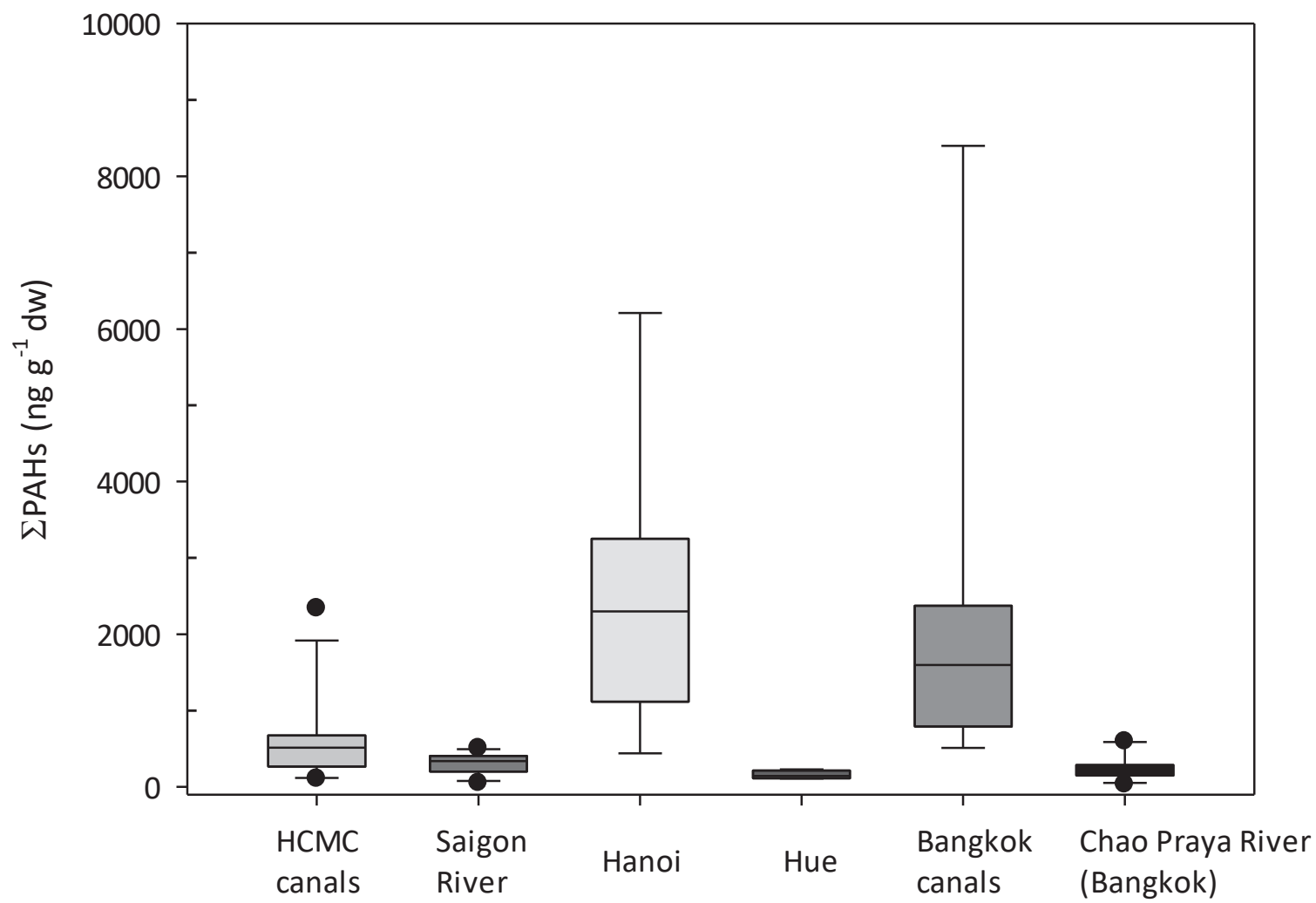

Figure 3-Box-plot of $\Sigma$ PAHs concentrations in various locations in southeast Asia (HCMC canals and Saigon River, this study and (Bui et al., 2016); Hanoi and Hue data from (Kishida et al., 2007); Bangkok canals and Chao Praya

River data from (Boonyatumanond et al., 2006)

Emission patterns might differ among these cities. Boonyatumanond et al. analyzed triterpanes (markers of petroleum origin) in Bangkok canal and Chao-Praya River sediments, and compared the molecular profiles in sediments and urban dust (Boonyatumanond et al., 2006). They concluded that road traffic was one of the major sources of PAHs in canals, while a mixture of petrogenic and pyrogenic sources was demonstrated in the lower Chao-Praya River. Soil erosion due to frequent heavy rains was also suggested as a PAH pathway to the aquatic system. In Hanoi sediments it was also claimed that PAH concentrations were the consequence of a mixture of domestic (cooking), industrial and road traffic related sources, the latter being a major contributor (Boll et al., 2008). These South-Asian cities therefore have in common with HCMC that road traffic is a major PAH source, as illustrated by similar individual PAH ratios (Figure S2 in the SI). PAHs from road traffic further deposit on urban surfaces, either directly or after a stage in the atmosphere. 
While pointing out low PAH concentrations in Malaysian rivers, estuaries and coastal sediments compared to Tokyo and other industrialized areas, Zakaria et al. showed by several means that petrogenic inputs were a major control factor of $\Sigma$ PAHs concentrations in this set of locations (Zakaria et al., 2002). They claimed that street dust might represent $30 \%$ or more of $\Sigma \mathrm{PAHs}$ in some sediment samples. They suggested that urban runoff generated by heavy tropical rains wash out land-based pollutants to aquatic media more effectively than at higher latitudes characterized by less intense rainfall (Zakaria et al., 2002). Boonyatumanond et al. also noticed that $\Sigma$ PAHs in Bangkok were low compared to other cities around the world, and attributed the lower levels they observed to climatic factors, which would have enhanced PAH degradation (Boonyatumanond et al., 2006). We argue that this cannot actually explain the differences among the three large cities recorded in Figure 3, which experience similar climatic conditions, nor the contrast between canal and river sediments in Bangkok and HCMC. On the other hand, heavy rains (monsoon) occur in Bangkok (mean 1650 mm per year; TMD, 2018) as in Hanoi (mean $1680 \mathrm{~mm}$ per year; GSO, 2016). These rainfall records are comparable to HCMC (1800 mm), and would provoke similar surface runoff on impervious urban surfaces and transfer of PAH contaminated particles to urban waterways in the three cities.

In addition to degradation processes, several factors control sedimentary PAH concentrations in surface sediments, in particular (i) the rate of $\mathrm{PAH}$ input, (ii) the rate of sediment input, (iii) the resuspension and redeposition of PAHs and sediment particles, and (iv) some vertical mixing due to biological or physical processes (Boonyatumanond et al., 2006). While potentially significant at small spatial scales, bioturbation (i.e., vertical mixing due to biological processes) should be less influential at larger spatial scales than processes involving sediment particle movements in a dynamic system. An attempt to summarize the interplay of these processes is presented in Figure 4. As discussed above, we assume that PAH input rates are similar in Bangkok, Hanoi and HCMC. PAHs are emitted to the atmosphere by industries or road traffic, and later deposited on urban surfaces. PAHs may also be released directly in canals or into the river by industries. Only these two sources are presented for the sake of clarity; complementary sources, e.g., biomass burning, also emit PAHs to the atmosphere, so adding this type of source would not significantly change our comprehension of PAH fate in this system. Sediment rates of inputs in the Saigon River are influenced by the Dau Tieng reservoir, which decreases the overall particle flux from upstream, and releases finer particles. Inputs from the city, i.e., canal sediments, are probably limited during the dry season, because most canal downstream ends are closed by floodgates, so as to prevent flooding 
in more exposed urban areas (Ngoc et al., 2016). As a consequence of the succession of flow and ebb tides,

exceeding by far the net flow of the Saigon River (Camenen et al., 2017), sediment particles are in the meantime brought from downstream, i.e. from the Dongnai River and the estuary, deposited and resuspended, Nevertheless, according to the flow velocity of $1.0-1.5 \mathrm{~m} \mathrm{sec}^{-1}$ (Camenen et al., 2017), the net deposition rate should be low. Thus the PAH load in Saigon River sediments might be low in the dry season because of the dilution caused by this redistribution of sediment particles in the river and the low PAH inputs (Figure 4-A). The same presumably arises in Chao Praya River in Bangkok, which is subjected to tidal influence (Chinnarasri and Kemden, 2016), but not in Hanoi, which is far from the sea (Luu et al., 2010).

This pattern changes drastically during the monsoon (Figure 4-B). Under heavy rain, high volumes of water are discharged first on urban surfaces, where they wash out deposited PAHs, then into the canals. At ebbing tide, floodgates open, so as to drain off the rainwater. As a consequence, urban dust as well as canal sediments will be flushed to the Saigon River. The net Saigon downstream flow increases in this season by a factor of about 10 (Camenen et al., 2017), accelerating the sediment transfer towards the estuary. Sediment deposits in the estuary, in particular in the mangrove, might thus be more contaminated than Saigon River sediments. 

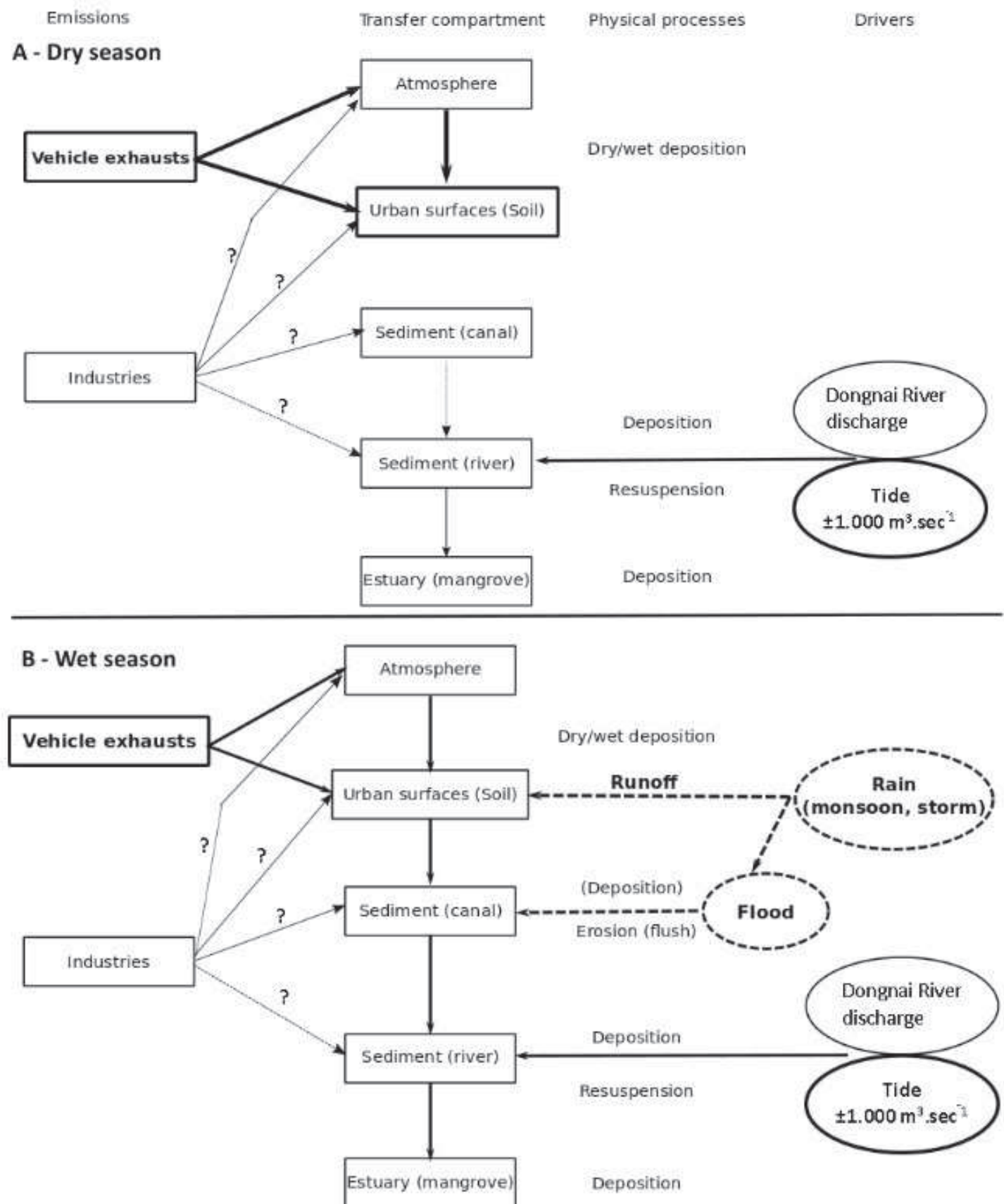

Figure 4 - Tentative scheme of PAH fate in the HCMC-Saigon-Dongnai river system

Can this scheme apply to other persistent organic chemicals, such as PBDEs or PFASs? No information could be

found in the literature on the occurrence of PBDEs in HCMC sediments, nor in other media. Low PBDE concentrations were found some years ago in catfish from the Mekong River delta (Minh et al., 2006). These compounds were recently found in sediments from rivers and lakes in the Hanoi region, with concentrations ranging between 0.04 and $17.5 \mathrm{ng} \mathrm{g}^{-1}(\mathrm{dw})$ for the sum of seven congeners representing the most common PBDE technical mixtures (Mai et al., 2018). They were also found in Hanoi road dust, at concentrations comparable to 
those from Chinese cities (Anh et al., 2018). Furthermore, a large PBDE monitoring study focusing on sediment samples collected from urban canals or rivers in Lao PDR, Cambodia, Vietnam, India, Indonesia, Thailand, the Philippines, Malaysia and Japan, including four samples from Hanoi, claimed that there was a relationship between the gross domestic product (GDP) per capita in emergent countries and $\Sigma$ PBDE concentrations in urban river sediments (Kwan et al., 2013). The predominant congener in this study was BDE209 (43-97\% of $\Sigma$ PBDE), which was not analyzed in HCMC samples. PBDE emissions in HCMC are therefore likely comparable to Hanoi emissions, although there is currently no direct evidence for this. The fact that PBDEs remained undetected in Saigon River sediments is accordingly consistent with the framework described above for PAHs.

As mentioned above, there are a few data attesting of the contamination of HCMC waters by PFCAs and PFSAs (Duong et al., 2015; Lam et al., 2017). Concentrations up to $9.2 \mathrm{ng} \mathrm{L}^{-1}$ for PFHpA, $5.6-5.8 \mathrm{ng} \mathrm{L^{-1 }}$ for PFHxA and PFPeA, and $18 \mathrm{ng} \mathrm{L}^{-1}$ for PFOA were observed at some canal sites (Duong et al., 2015). Lam et al. (2017) searched for a wider range of PFASs and investigated several environmental compartments, and identified long-chain PFCAs in some sediment samples. Both studies support consistent PFAS emissions from numerous kinds of sources, including consumers products (Duong et al., 2015), industries (metal, textile, paper) and domestic waste water discharges (Lam et al., 2017). Beside PFCAs and PFSAs, FTSAs were also identified in 47-65 \% of sediment samples, as well as di-PAPs (65-88\%), The former compounds arise from the degradation of fluorotelomer-based substances (precursors) used, for example, in firefighting foams or food-packaging, applications and were found in waste waters in several instances (Buck et al., 2011). Polyfluoroalkyl phosphoric acid di-esters (di-PAPs) are used primarily for their surfactant properties in various applications such as food-packaging or a defoaming agent in pesticide formulations (Buck et al., 2011) and were found in waste waters (D'Eon et al., 2009). PFASs (PFCAs, PFSAs or precursors of these acids) have also been identified in rainwater and runoff in urban areas (Zhao et al., 2013). Cumulative rainwater was associated with PFBA and PFBS in the dissolved phase of an urban tropical catchment, suggesting these compounds were mainly brought into the water body by runoff, while several other PFASs originated from point sources (Chen et al., 2017). There are accordingly consistent indications pointing to PFAS emissions in HCMC's environment, although the balance between the routes might differ from that of PAHs, especially considering the fact that atmospheric deposition is unlikely a major source of PFASs in densely populated areas (Lindim et al., 2015). 


\section{Conclusion}

We searched for a wide range of organic contaminants in bed sediments from the Saigon River, and a few adjacent canals. Measured concentrations were below the LOD for PBDEs and some PFASs, and low for DDT, PCBs, PAHs and several PFASs, except for the insecticides chlorpyrifos-ethyl and $\lambda$-cyhalothrin at a few places.

We explain the low concentrations observed by the strong tidal influence, which hinders the accumulation of sediments in the Saigon River channel, and the runoff on urban surfaces during the monsoon. This contamination transfer pattern raises concerns about potential impacts further downstream in depositional areas such as the Can Gio mangrove (Schwarzer et al., 2016), an ecosystem providing important services, in particular fisheries (Vo and Kuenzer, 2013).

\section{Acknowledgements}

This study was supported by the Auvergne-Rhône-Alpes Region, through the CMIRA-Coopera program, "Saigon River: la ville et le fleuve, 2015-2017" project. We thank the Centre Asiatique de Recherche sur l'Eau (CARE) staff in Ho Chi Minh City for their kind and efficient help during field work, as well as EPFL in Lausanne which co-funded a part of the analytical work. We also thank Thanh-Kiet Bui and Carmen Casado-Martinez who kindly provided data from their own field work in Ho Chi Minh City. We thank Linda Northrup (English Solutions, Voiron, France), for copy-editing the manuscript.

\section{References}

Ahrens, L., Taniyasu, S., Yeung, L.W.Y., Yamashita, N., Lam, P.K.S., Ebinghaus, R., 2010. Distribution of polyfluoroalkyl compounds in water, suspended particulate matter and sediment from Tokyo Bay, Japan. Chemosphere 79, 266-272

Anh, H.Q., Tomioka, K., Tue, N.M., Tri, T.M., Minh, T.B., Takahashi, S., 2018. PBDEs and novel brominated flame retardants in road dust from northern Vietnam: Levels, congener profiles, emission sources and implications for human exposure. Chemosphere 197, 389-398,10.1016/j.chemosphere.2018.01.066.

Bertin, D., Ferrari, B.J.D., Labadie, P., Sapin, A., Garric, J., Budzinski, H., Houde, M., Babut, M., 2014. Bioaccumulation of perfluoralkyl compounds in midge (Chironomus riparius) larvae exposed to sediment. Environ. Pollut. 189, 27-34,http://dx.doi.org/10.1016/j.envpol.2014.02.018.

Blott, S.J., Pye, K., 2001. Gradistat: A grain size distribution and statistics package for the analysis of unconsolidated sediments. Earth Surface Processes and Landforms 26, 1237-1248,10.1002/esp.261.

Boll, E.S., Christensen, J.H., Holm, P.E., 2008. Quantification and source identification of polycyclic aromatic hydrocarbons in sediment, soil, and water spinach from Hanoi, Vietnam. Journal of Environmental Monitoring 10, 261-269,10.1039/b712809f.

Boonyatumanond, R., Wattayakorn, G., Togo, A., Takada, H., 2006. Distribution and origins of polycyclic aromatic hydrocarbons (PAHs) in riverine, estuarine, and marine sediments in Thailand. Marine Pollution Bulletin 52, $942-$ 956,10.1016/j.marpolbul.2005.12.015.

Buck, R.C., Franklin, J., Berger, U., Conder, J.M., Cousins, I.T., de Voogt, P., Jensen, A.A., Kannan, K., Mabury, S.A., van Leeuwen, S.P.J., 2011. Perfluoroalkyl and polyfluoralkyl substances in the environment: terminology, classification, and origins. Integr. Environ. Assess. Manag. 7, 513-541,10.1002/ieam.258.

Bui, T.-K.L., Do Hong, L.C., Combi, T., Lara-Martin, P.A., Casado-Martinez, M.C., Werner, I., 2016. Sediment quality assessment in Ho Chi Minh City canals. SETAC Europe, Nantes (Fr). 
Camenen, B., Dramais, G., Le Coz, J., Ho, T.-D., Gratiot, N., Piney, S., 2017. Estimation of a water level - Discharge rating curve for a river influenced by the tide [Estimation d'une courbe de tarage hauteur-dénivelée-débit pour une rivière influencée par la marée]. Houille Blanche, 16-21,https://doi.org/10.1051/lhb/2017039.

Chen, H., Reinhard, M., Nguyen, T.V., You, L., He, Y., Gin, K.Y.-H., 2017. Characterization of occurrence, sources and sinks of perfluoroalkyl and polyfluoroalkyl substances (PFASs) in a tropical urban catchment. Environ. Pollut. 227, 397-405,https://doi.org/10.1016/j.envpol.2017.04.091.

Cheng, F., Li, H., Qi, H., Han, Q., You, J., 2017. Contribution of pyrethroids in large urban rivers to sediment toxicity assessed with benthic invertebrates Chironomus dilutus: A case study in South China. Environmental Toxicology and Chemistry 36, 3367-3375,10.1002/etc.3919.

Chinnarasri, C., Kemden, N., 2016. Discharge estimation of a tidal river with reverse flow: Case of the Chao Phraya River, Thailand. Journal of Hydrologic Engineering 21,10.1061/(ASCE)HE.1943-5584.0001323.

D'Eon, J.C., Crozier, P.W., Furdui, V.I., Reiner, E.J., Libelo, E.L., Mabury, S.A., 2009. Perfluorinated phosphonic acids in Canadian surface waters and wastewater treatment plant effluent: discovery of a new class of perfluorinated acids. Environ. Toxicol. Chem. 28, 2101-2107

de Boer, J., Allchin, C., Law, R., Zegers, B., Boon, J.P., 2001. Method for the analysis of polybrominated diphenylethers in sediments and biota. TrAC - Trends in Analytical Chemistry 20, 591-599,10.1016/S01659936(01)00097-8.

Du, P.T., Fukushima, S., 2009. Transformation of socio-economic structure of Ho Chi Minh City under the Doi Moi policy and the accompanying globalization process. Meijo Asian Research Journal 1, 33-45

Duong, H.T., Kadokami, K., Shirasaka, H., Hidaka, R., Chau, H.T.C., Kong, L., Nguyen, T.Q., Nguyen, T.T., 2015. Occurrence of perfluoroalkyl acids in environmental waters in Vietnam. Chemosphere 122, 115124,10.1016/j.chemosphere.2014.11.023.

GSO, 2016. Ho Chi Minh City Statistical Yearbook 2016. in: Office, G.S.O.o.V.-H.C.M.C.S. (Ed.), p. 358.

Gubry, P., Lortic, B., Grenèche, G., Van Thanh, L., Thi Huong, L., Thi Than Thuy, T., Thi Tieng, N., Thuy Huong, P., Hoang Ngan, V., The chinh, N., 2002. Hô Chi Minh Ville et Hanoi : Population et migrations intra-urbaines in: ISTED, G. (Ed.). Regards croisés sur Hanoi : Transition, spécificité urbaine et choix de développement. Institut de Recherche pour le Développement (IRD); Institut de recherche économique de Ho Chi Minh Ville (IRE); Centre de Population, Université Nationale d'Economie, Hanoi (CP), Hanoï (Vietnam), p. 42.

Ha, N.T.V., 2009. Integrated study on factors affecting water quality of the Saigon River system in Vietnam. Urban Engineering. Tokyo (Japan), Tokyo, p. 230.

Heiri, O., Lotter, A.F., Lemcke, G., 2001. Loss on ignition as a method for estimating organic and carbonate content in sediments: Reproducibility and comparability of results. Journal of Paleolimnology 25, 101110,10.1023/A:1008119611481.

HEPZA.2018-03-05, http://www.hepza.hochiminhcity.gov.vn/web/guest/kcn_kcx-tphcm/bang-gia-dat

Hung, C.V., Cam, B.D., Mai, P.T.N., Dzung, B.Q., 2014. Heavy metals and polycyclic aromatic hydrocarbons in municipal sewage sludge from a river in highly urbanized metropolitan area in Hanoi, Vietnam: levels, accumulation pattern and assessment of land application. Environmental Geochemistry and Health 37, 133$146,10.1007 /$ s10653-014-9635-2.

Ineris.Portail des substances chimiques (request lambda-cyhalothrine). 2017.04.14, http://www.ineris.fr/substances/fr/substance/1153

Kilunga, P.I., Sivalingam, P., Laffite, A., Grandjean, D., Mulaji, C.K., de Alencastro, L.F., Mpiana, P.T., Poté, J., 2017. Accumulation of toxic metals and organic micro-pollutants in sediments from tropical urban rivers, Kinshasa, Democratic Republic of the Congo. Chemosphere 179, 37-48,10.1016/j.chemosphere.2017.03.081.

Kishida, M., Imamura, K., Maeda, Y., Lan, T.T.N., Thao, N.T.P., Pham, H.V., 2007. Distribution of persistent organic pollutants and polycyclic aromatic hydrocarbons in sediment samples from Vietnam. Journal of Health Science 53, 291-301,10.1248/jhs.53.291.

Kwan, C.S., Takada, H., Mizukawa, K., Saha, M., Rinawati, Santiago, E.C., 2013. Sedimentary PBDEs in urban areas of tropical Asian countries. Marine Pollution Bulletin 76, 95105,https://doi.org/10.1016/j.marpolbul.2013.09.023.

Lam, N.H., Cho, C.-R., Kannan, K., Cho, H.-S., 2017. A nationwide survey of perfluorinated alkyl substances in waters, sediment and biota collected from aquatic environment in Vietnam: Distributions and bioconcentration profiles. Journal of Hazardous Materials 323, 116-127,https://doi.org/10.1016/j.jhazmat.2016.04.010.

Lindim, C., Cousins, I.T., vanGils, J., 2015. Estimating emissions of PFOS and PFOA to the Danube River catchment and evaluating them using a catchment-scale chemical transport and fate model. Environ. Pollut. 207, 97106,http://dx.doi.org/10.1016/j.envpol.2015.08.050. 
Luu, T.N.M., Garnier, J., Billen, G., Orange, D., Némery, J., Le, T.P.Q., Tran, H.T., Le, L.A., 2010. Hydrological regime and water budget of the Red River Delta (Northern Vietnam). Journal of Asian Earth Sciences 37, 219228,10.1016/j.jseaes.2009.08.004.

MacDonald, D.D., Ingersoll, C.G., Berger, T.A., 2000. Development and evaluation of consensus-based sediment quality guidelines for freshwater ecosystems. Archives of Environmental Contamination and Toxicology 39, 2031

Mai, P.T.N., Van Thuong, N., Tham, T.T., Hoang, N.K., Anh, H.Q., Tri, T.M., Hung, L.S., Nhung, D.T., Nam, V.D., Hue, N.T.M., Huong, N.T.A., Anh, D.H., Minh, N.H., Minh, T.B., 2018. Distribution, accumulation profile, and risk assessment of polybrominated diphenyl ethers in sediment from lake and river systems in Hanoi Metropolitan Area, Vietnam. Environmental Science and Pollution Research 25, 7170-7179,10.1007/s11356-015-5235-7.

Minh, N.H., Minh, T.B., Iwata, H., Kajiwara, N., Kunisue, T., Takahashi, S., Viet, P.H., Tuyen, B.C., Tanabe, S., 2007. Persistent organic pollutants in sediments from Sai Gon-Dong Nai River basin, Vietnam: Levels and temporal trends. Archives of Environmental Contamination and Toxicology 52, 458-465,10.1007/s00244-006-0157-5.

Minh, N.H., Tu, B.M., Kajiwara, N., Kunisue, T., Iwata, H., Pham, H.V., Tu, N.P.C., Bui, C.T., Tanabe, S., 2006. Contamination by polybrominated diphenyl ethers and persistent organochlorines in catfish and feed from Mekong River Delta, Vietnam. Environmental Toxicology and Chemistry 25, 2700-2708,10.1897/05-600R.1.

Munoz, G., Giraudel, J.-L., Botta, F., Lestremau, F., Dévier, M.-H., Budzinski, H., Labadie, P., 2015. Spatial distribution and partitioning behavior of selected poly- and perfluoroalkyl substances in freshwater ecosystems: A French nationwide survey. Sci. Tot. Environ. 517, 48-56,http://dx.doi.org/10.1016/j.scitotenv.2015.02.043. Munoz, G., Labadie, P., Botta, F., Lestremau, F., Lopez, B., Geneste, E., Pardon, P., Dévier, M.H., Budzinski, H., 2017. Occurrence survey and spatial distribution of perfluoroalkyl and polyfluoroalkyl surfactants in groundwater, surface water, and sediments from tropical environments. Sci. Tot. Environ. 607-608, 243252,10.1016/j.scitotenv.2017.06.146.

Mwanamoki, P.M., Devarajan, N., Thevenon, F., Birane, N., de Alencastro, L.F., Grandjean, D., Mpiana, P.T., Prabakar, K., Mubedi, J.I., Kabele, C.G., Wildi, W., Poté, J., 2014. Trace metals and persistent organic pollutants in sediments from river-reservoir systems in Democratic Republic of Congo (DRC): Spatial distribution and potential ecotoxicological effects. Chemosphere 111, 485-492,10.1016/j.chemosphere.2014.04.083.

Ngoc, T.D.T., Perset, M., Strady, E., Phan, T.S.H., Vachaud, G., Quertamp, F., Gratiot, N., 2016. Ho Chi Minh City growing with water-related challenges. Water, megacities and global change : portraits of 15 emblematic cities of the world. UNESCO ; ARCEAU, Paris, p. 27.

Nguyen, N.V., 2009. Occurrence of Persistent Toxic Substances in Soils, Sediments, Fishes and Human Breast Milk in Southern Vietnam. Ecole Polytechnique Fédérale de Lausanne, Lausanne, p. 272.

Phuong, P.K., Son, C.P.N., Sauvain, J.-J., Tarradellas, J., 1998. Contamination by PCB's, DDT's, and heavy metals in sediments from Ho Chi Minh City's canals, Vietnam. Bulletin of Environmental Contamination and Toxicology 60, 347-354

Schwarzer, K., Thanh, N.C., Ricklefs, K., 2016. Sediment re-deposition in the mangrove environment of Can Gio, Saigon River estuary (Vietnam). 1, 138-142,10.2112/SI75-028.1.

Strady, E., Dang, V.B.H., Némery, J., Guédron, S., Dinh, Q.T., Denis, H., Nguyen, P.D., 2016. Baseline seasonal investigation of nutrients and trace metals in surface waters and sediments along the Saigon River basin impacted by the megacity of Ho Chi Minh (Vietnam). Environmental Science and Pollution Research, 118,10.1007/s11356-016-7660-7.

Thevenon, F., de Alencastro, L.F., Loizeau, J.L., Adatte, T., Grandjean, D., Wildi, W., Poté, J., 2013. A highresolution historical sediment record of nutrients, trace elements and organochlorines (DDT and PCB) deposition in a drinking water reservoir (Lake Brêt, Switzerland) points at local and regional pollutant sources. Chemosphere 90, 2444-2452,10.1016/j.chemosphere.2012.11.002.

TMD.30.06.2018, https://www.tmd.go.th/en/climate.php?FileID=7

UNEP, 2014. Bi-ennal Global Interlaboratory Assessment on Persistent Organic Pollutants. United Nations Environment Programme - Chemicals Branch - Division of Technology, Industry and Economics, p. 90.

Vo, T.Q., Kuenzer, C., 2013. Can Gio Mangrove Biosphere Reserve Evaluation of current Status, Dynamics, and Ecosystem Services, 2012. in: Nature, I.U.f.t.C.o. (Ed.). IUCN, p. 109.

World-Bank, 2009. Vietnam - PCB Management Project. World Bank, p. 106.

Yunker, M.B., Macdonald, R.W., Vingarzan, R., Mitchell, R.H., Goyette, D., Sylvestre, S., 2002. PAHs in the Fraser River basin: A critical appraisal of PAH ratios as indicators of PAH source and composition. Organic Geochemistry 33, 489-515,10.1016/S0146-6380(02)00002-5.

Zakaria, M.P., Takada, H., Tsutsumi, S., Ohno, K., Yamada, J., Kouno, E., Kumata, H., 2002. Distribution of polycyclic aromatic hydrocarbons (PAHs) in rivers and estuaries in Malaysia: A widespread input of petrogenic PAHs. Environmental Science and Technology 36, 1907-1918,10.1021/es011278+. 
Zhang, L., Qin, Y., Zheng, B., Lin, T., Li, Y., 2013. Polycyclic aromatic hydrocarbons in the sediments of Xiangjiang River in south-central China: occurrence and sources. Environmental Earth Sciences 69, 119125,10.1007/s12665-012-1939-x.

Zhao, L., Zhou, M., Zhang, T., Sun, H., 2013. Polyfluorinated and Perfluorinated Chemicals in Precipitation and Runoff from Cities Across Eastern and Central China. Arch. Environ. Contam. Toxicol. 64, 198207,10.1007/s00244-012-9832-x. 